\title{
Study on the Release and Bioevaluations of Green Silver Nanoparticles Entrapped Inside Polymer-based Nanovesicles
}

\author{
MARIA PROKS ${ }^{1 \#, ~ F L O R I N ~ B O R C A N #, ~ A D E L I N A ~ C H E V E R E S A N " 1 \#, ~ I U L I A ~ P I N Z A R U ², ~ B O G D A N ~ A L M A J A N ~ G U T A 3 *, ~}$ \\ DORINA CORICOVAC' ${ }^{2}$ VIRGIL PAUNESCU ${ }^{1}$, VOICHITA LAZUREANU ${ }^{1}$ \\ ${ }^{1}$ Victor Babes University of Medicine and Pharmacy, Faculty of Medicine,2 Eftimie Murgu Sq., 300041, Timisoara, Romania \\ 2Victor Babes University of Medicine and Pharmacy, Faculty of Pharmacy,2 Eftimie Murgu Sq., 300041, Timisoara, Romania \\ ${ }^{3}$ West University of Timisoara, 4 Vasile Parvan Blvd., 300223, Timisoara, Romania
}

\begin{abstract}
The drug carriers represent a very important and modern pathway used to increase the therapeutic efficacy of the natural active substances. Nano-sized assemblies of noble metals and herbal extracts represent very simple, cheap, biologically and ecologically friendly synthesis. The main aims of this study were to obtain polyurethane nanovesicles containing silver nanoparticles and to evaluate their release rate. The vesicles' sizes, homogeneity and surface charge were studied using a Cordouan Technol. Zetasizer, while the thermal behaviour was assessed by DSC. UV-Vis measurements were done to evaluate the release rate. Toxicological effects were studied by non-invasive techniques on human skin. The results suggest the obtaining of homogenous polyurethane nanovesicles between 80 and $95 \mathrm{~nm}$, with positive surface charge, very good thermal stability and a prolonged release. The non-irritation potential recommends these vesicles as a safe carrier for different herbal extracts.
\end{abstract}

Keywords: drug carrier, erythema, mexametry, polyurethane, TEWA, thyme, Zetasizer

The spontaneous or cultured thyme is a powerful aromatic plant used since antiquity in different Mediterranean recipes, cosmetics and for the treatment of some diseases, but its consecration as medicine came in the Middle Ages when the Arabs began to produce volatile oils by distillation, oils which were capable of healing the plagues that decimated the population of those times [1]. Today, thyme is not missing from the kitchen of any housewife, and it is also used as a natural remedy of digestion problems / abdominal cramps, kidney infections, and respiratory diseases (laryngitis, sinusitis, chronic bronchitis, asthma, convulsive cough or productive cough) [2].

Thyme extracts present wide-antibacterial spectrum, antifungal, antimycotic, antiparasitic, antiviral and potent analgesic effects and they are used as repellent for insects, for scalp problems, in cutaneous applications (acne, mycosis, dermatosis or various infectious problems); they stimulate the immune system, the nervous system, and they help the respiratory system. The main components of thyme extracts are: thymol (around 30\%), carvacrol ( 1/ $4 \mathrm{w} / \mathrm{w}$ ), therpynyl acetate (more than $30 \%$ ) (fig. 1). Alphaand beta-pinene, 1,8-cineole, camphor, borneol, linalool, gamma-terpinene and terpinolen were also found in the composition of thyme essential oils by Varga et al. [3] .

A main research field of the modern pharmacy is the increasing of the therapeutically efficacy. The therapeutically efficacy of a certain active substance is related to its dose, but an increased amount often have different toxic effects. The drug delivery systems were developed to modify the administration mechanism of active substances and the results are amazing.
The main target of this research is to obtain polymerbased nanovesicles and to study the release rate of some silver nanoparticles containing active principles of thyme extracts.

\section{Experimental part}

L-lysine was achieved from Sigma-Aldrich (Germany, EU), 1,4-butanediol (BD) from Carl Roth GmbH (Germany, EU), isophorone-diisocyanate (IPDI), polyethylene-glycol, $M \sim 200$ (PEG), silver nitrate, Span ${ }^{\circledR} 85$ and acetone from Merck (Germany, EU). All the others substances necessary for samples purification and for the degradation medium $\left(\mathrm{NaHCO}_{3}, \mathrm{Na}_{2} \mathrm{HPO}_{4^{\prime}} \mathrm{NaCl}, \mathrm{KH}_{2} \mathrm{PO}_{4^{\prime}} \mathrm{K}_{2} \mathrm{HPO}_{4}, \mathrm{KCl}\right.$ and $\mathrm{MgCl}_{2}$ ) and $\mathrm{HCl}^{3}$ solution ${ }^{\prime} \mathrm{M}$ were obtained from SC Chimopar Trading SRL (Romania, EU). The inorganic salts (analytical grade) were previously heated at $125^{\circ} \mathrm{C}$ for $1 / 2 \mathrm{~h}$ in order to remove the crystallization water.

The obtaining of silver nitrate nanoparticles is a green procedure described in the literature by Alomri et al. [4]: 5.00 grams thyme partially dried plants were well washed and cut very softly and then they were incubated as an aqueous solution ( $2 \% \mathrm{w} / \mathrm{v}$ ) in an Erlenmeyer flask at 75 $80^{\circ} \mathrm{C}$ for two hours; the solution was decanted and filtered. $20 \mathrm{mg}$ silver nitrate was mixed with $100 \mathrm{~mL}$ filtrate at room temperature and normal pressure. Silver nanoparticles were then centrifuged at $4500 \mathrm{rpm}$, they were repeatedly washed with double distilled water, and concentrated for further synthesis.

The polymer-based nanovesicles were obtained followed a procedure which was presented in our previous papers [5-8]:

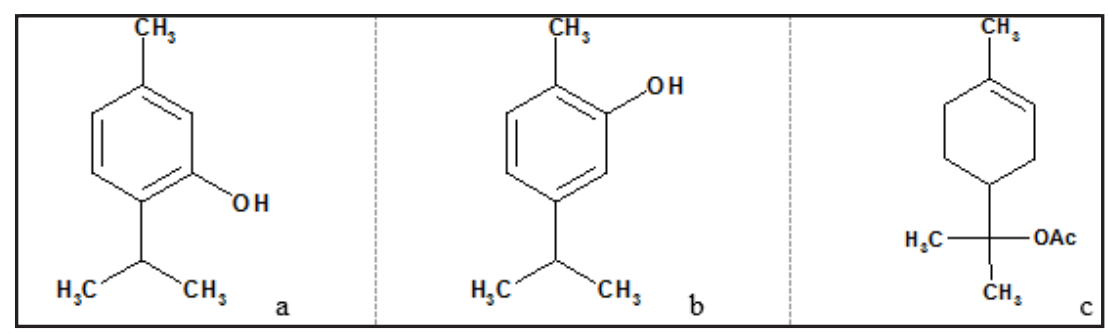

Fig. 1. Chemical structures of (a) thymol,

(b) carvacrol and (c) therpynyl acetate 
- Non-aqueous component: $1.70 \mathrm{~mL} \quad$ Span $^{\circledR} 85$ was added to $35 \mathrm{~mL}$ solution IPDI in acetone (10\%, v/v) and were magnetic stirred at $430 \mathrm{rpm}$ and $30^{\circ} \mathrm{C}$ for $25 \mathrm{~min}$;

- Aqueous component: $50 \mathrm{~mL}$ mixture of $\mathrm{BD}$ and PEG in distilled water $(0.15: 1: 20, \mathrm{v} / \mathrm{v} / \mathrm{v})$ was homogenized at 430 rpm and $30^{\circ} \mathrm{C}$ for $25 \mathrm{~min}$;

- The two components were mixed under magnetic stirring at $580 \mathrm{rpm}$ and $40^{\circ} \mathrm{C}$; the stirring continued with the same rotation speed for $4 \mathrm{~h}$ to ensure the maturation of polyurethane vesicles walls;

- Products purification: the suspensions were dried as thin layers at $55^{\circ} \mathrm{C}$ for $\sim 24 \mathrm{~h}$ and then, they were repeatedly washed with a double distilled water-acetone mixture $(1: 1.4, v / v)$, and centrifuged at $3000 \mathrm{rpm}$.

This multi-step protocol was repeated twice in order to obtain different samples: SO (empty vesicles) and S1 (polyurethane nanovesicles containing silver nanoparticles with thyme extract); the silver nanoparticles were added inside the aqueous component.

A Zetasizer equipment from Cordouan Technol. (France, EU) containing a Particle Size Analyzer (Vasco) and a Zeta potential Analyzer (Wallis) was used to assessed the vesicles' surface charge and size; diluted solutions (1:200 $\mathrm{w} / \mathrm{v}$ ) of the two samples were used and the following parameters were set: determination temperature $\left(27 \pm 0.5^{\circ} \mathrm{C}\right)$, time interval $(\sim 14 \mu \mathrm{s})$, channels' no $(\sim 445)$, power of laser ( $\sim 85 \%)$, acquisition mode (continuous), Pade-Laplace as analysis mode, a medium resolution for Zeta potential determinations, and Smoluchowski model as Henry function.

A DSC1 instrument from Mettler-Toledo (Switzerland) was used to record the thermal behaviour of samples between 30 and $300^{\circ} \mathrm{C}$ in an inert atmosphere using aluminum crucibles with perforated caps and a 5 degree/ minute heating rate.

The procedure used to evaluate the drug release rate from a polyurethane drug delivery system was described by Albulescu etal. [9]. Main components of thyme extracts, flavonoids and quinines obtained by polyphenols oxidation, are detectable at $417 \mathrm{~nm}$ according to Bunghez et al. [10]. A UVi Line 9400 Spectrophotometer from SI Analytics (Germany, EU) and Beer-Lambert law were used to determine the amount of free silver nanoparticles content at every third day for 2 weeks while the nanovesicles were maintained in a degradation medium at a neutral $\mathrm{pH}$.

Six men and nine women, between 18 and 26 years old, were enrolled in this study to assess the toxicological effects of the synthesized samples. All principles of the Helsinki Declaration and the local jurisdiction have been respected, and the study was first approved by the Ethics Committee of our university; the volunteers read and signed informed consents. The samples $(0.25 \mathrm{~mL})$ were applied on their forearms (the left forearm for sample S1 and the right one for sample SO used as reference). The application areas were covered with skin-patches and the skin parameters' change was performed within $30 \mathrm{~min}$.

A Multiprobe Adapter System (MPA6) from Courage\& Khazaka (Germany, EU) equipped with a Tewameter, a Mexameter and a Corneometer probe was used to measure any change of trans-epidermal water loss, skin erythema and stratum corneum hydration level; the measurements were carried out by the same operator; ANOVA was used to determine any statistically significant differences; the following notations were used: ns for $P>0.05$, * for $P \leq$ 0.05 and $* *$ for $\mathrm{P} \leq 0.01$.

\section{Results and discussions}

The improvement of microbiological activity of different thyme extracts is very actual [11]. Alvarez Echazu et al. [12] developed chitosan hydrogels and assessed their antimicrobial-antioxidant activity for oral local delivery, while Zamani et al. [13] used cellulose derivatives as controlled release dosage form.

The nanoparticles, nanocapsules and nanotubes (structures with sizes below $100 \mathrm{~nm}$ ) represent an alternative drug administration in the lastyears due to their increased penetrability and encapsulation efficacy.

The green chemistry is a part of the chemical industry which is based on the following principles: the reducing of heavy metals, dichlorodiphenyl-trichloroethane (DDT) and chlorofluorocarbons (CFC); the reducing of natural resources; the pollution prevention; the reducing use of toxic raw materials and solvents during the new chemical syntheses; the increasing of the energetically efficiency and the recycling of the materials.

The evaluations of the polyurethane nanovesicles' sizes and homogeneity, respectively the Zeta potential values are presented in table 1.

No important change of the polyurethane nanovesicles sizes can be associated with the presence or the absence of silver nanoparticles; their sizes are inside a narrow range, under the limit of nano-/micro-scale, at $100 \mathrm{~nm}$. The polydispersity index shows that samples have an increased homogeneity degree, without different particles populations.

The polyurethane nanovesicles have a low tendency to agglomerate themselves; Salopek et al. [15] described that colloidal suspensions with Zeta potential values between 0 and $15 \mathrm{mV}$ are unstable systems, while the particles with values between 15 and $30 \mathrm{mV}$ present a medium stability against the tendency to form agglomerations.

The DSC diagrams (fig. 2) indicate the good thermal stability of the two samples in the studied temperatures' range: no important peak was found inside this temperature interval because the glass transitions of polyurethanes are below $25^{\circ} \mathrm{C}$ and the chains degradation begin over $300^{\circ} \mathrm{C}$, according to Citu et al. [16].

The two samples S0 and S1 were maintained inside a simulated physiological solution described in the literature by Gonzalez et al. [17]. Figure 3 shows that silver nanoparticles' release begins just after the fifth day and a good release rate (almost 50\%) is obtained at the end of the second week.

TEWAmetry, mexametry and corneometry are three modem and non-invasive techniques which can be involved in easy and cheap evaluations of new synthesized products intended to be used in different therapies. Any toxicological effect of chemical products is observable by the modification of the transpidermal water loss, skin erythema and the level of stratum corneum hydration; the changes

\begin{tabular}{|c|c|c|c|}
\hline Sample code & \multicolumn{2}{|c|}{ Particle size (nm) } & $\begin{array}{c}\text { Zeta potential } \\
(\mathrm{mV}) \text { Mean } \pm \text { SD }\end{array}$ \\
\cline { 2 - 4 } & Mean \pm SD & Polydispersity index & \\
\hline S0 & $84 \pm 7$ & 0.2 & $27.8 \pm 4.2$ \\
\hline S1 & $92 \pm 5$ & 0.4 & $25.4 \pm 4.9$ \\
\hline
\end{tabular}

Table 1

THE ZETASIZER CHARACTERISATION OF NANOVESICLES 


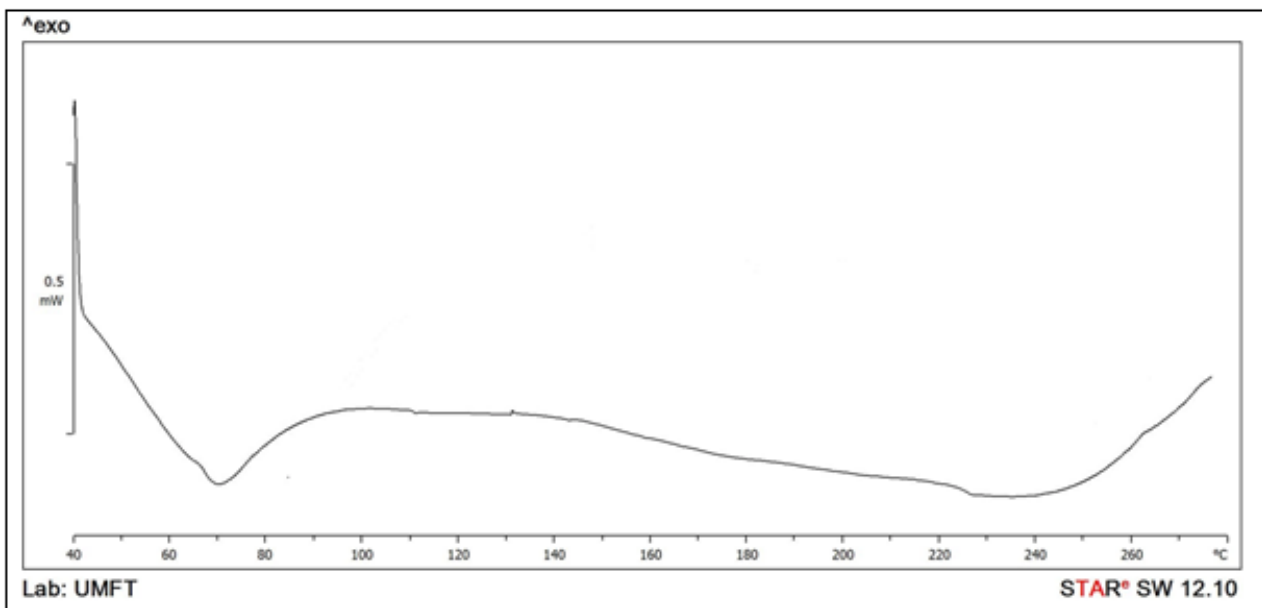

(a)

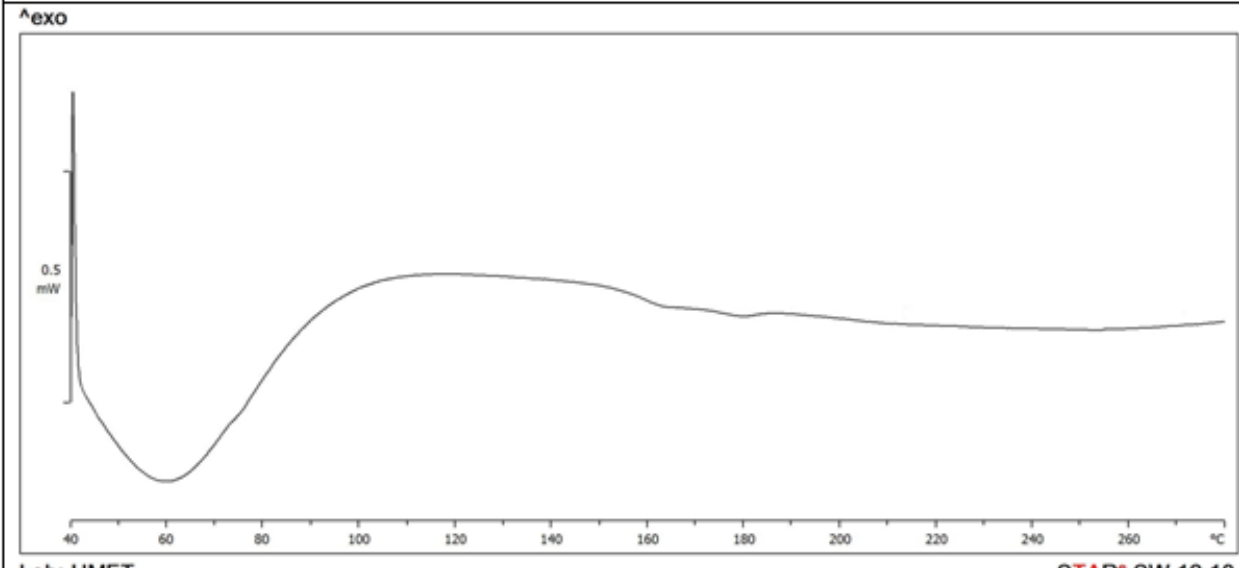

Lab: UMFT STAR $^{e}$ SW 12.10

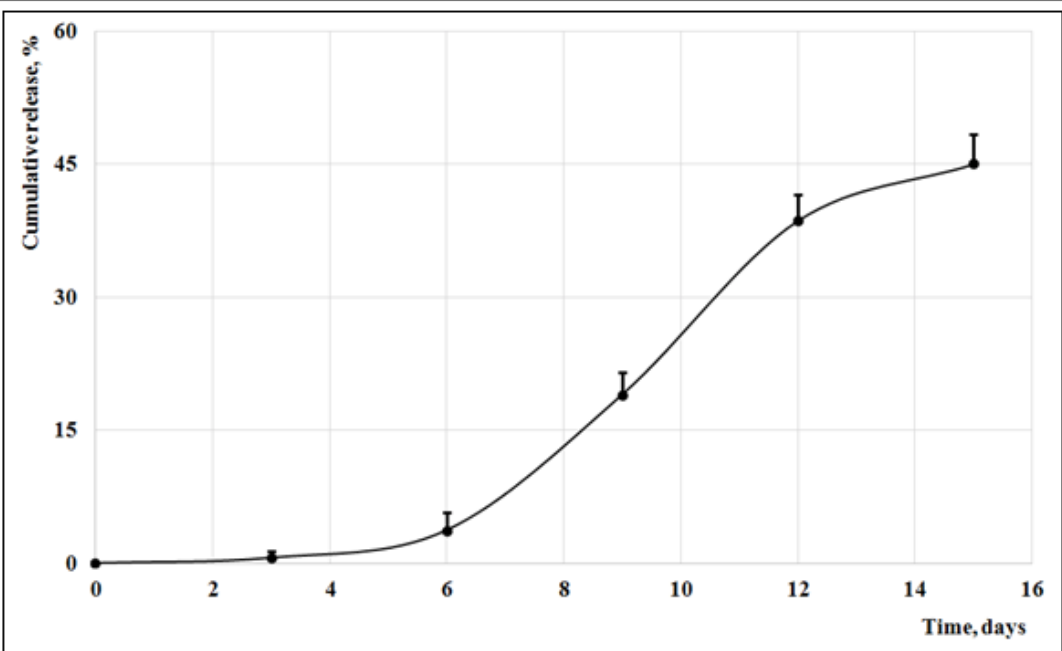

Fig. 3. The silver nanoparticles release profile

of these human skin parameters are presented in figure 4 a-c.

The skin plays an essential role in the protection of the body against external factors (physical and chemical agents); it is like a mirror that shows the health and the vitality of our body. It secretes sebum, eliminates toxins from the body and it reacts as a shield that defends us against the external aggressions - pollution, UV rays, cold, wind, smoke, and chemicals.

Any external aggression modifies the values of some skin parameters: the transepidermal water loss and the erythema increase very fast while the hydration level decrease. However, it is important to observe the speed of parameters change because the increases of TEWL betw een 1 and $10 \mathrm{~g} / \mathrm{h} / \mathrm{m}^{2}$ are specific to a normal process. In this research the TEWA change was just around 3-4 units during the study.
Fig. 2. DSC curves of polyurethane nanovesicles:

(a) So sample and (b) S1 sample 


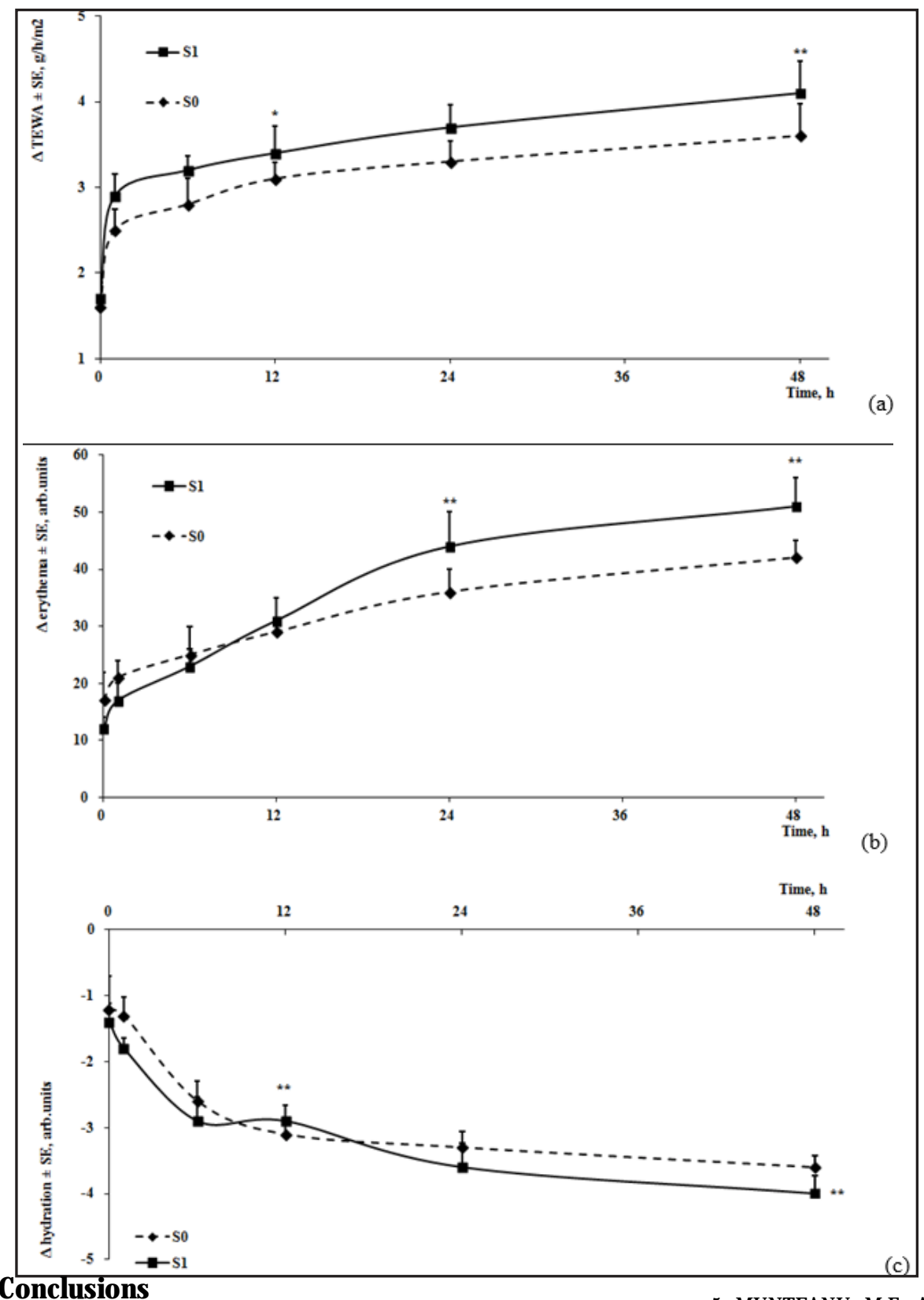

Fig. 4. Changes of human skin parameters: (a) TEWA, (b) erythema and $(\mathrm{c})$ hydration of stratum corneum

The synthesis of new polymer-based drug carriers used as transmembrane delivery systems for different herbal extracts represents a very important research field. This paper describes the synthesis of assembled silver nanoparticles in polyurethane nanovesicles and their characterization. Vesicles between 80 and $95 \mathrm{~nm}$, almost homogeneous with a positive surface charge (Zeta potential around $+26 \mathrm{mV}$ ), very stable between 30 and $300^{\circ} \mathrm{C}$ were obtained. The nanovesicles' toxicological behaviour was assayed using non-invasive procedures on human skin, such as transepidermal water loss, erythema and hydration measurements; no significant change was found during these tests and this is why we appreciate these polyurethane vesicles as a good alternative to the classical administration of thyme extracts.

\section{References}

1. WEISS ADAMSON, M. Food in Medieval Times. 2004. London: Greenwood Press.

2.***Natural Remedies Encyclopedia. Available at: https:// thesureword.org/wp-content/uploads/2016/11/The-Natural-RemediesEncyclopedia.pdf [October 2, 2018].

3. VARGA, E., BARDOCZ, A., BELAK, A., MARAZ, A., BOROS, B., FELINGER, A., BOSZORMENYI, A., HORVATH, G. Farmacia, 63, no. 3, 2015, p. 357.

4. ALOMRI, A.A., FARES, K.E.K., MOUSTAFA, N.E. Cogent Chemistry,

4, no. 1, 2018, p. 1.
5. MUNTEANU, M.F., ARDELEAN, A., BORCAN, F., TRIFUNSCHI, S.I., GLIGOR, R., ARDELEAN, S.A., CORICOVAC, D., PINZARU, I., ANDRICA, F., BORCAN, L-C. Current Drug Delivery, 14, no. 8, 2017, p. 1178.

6. BORCAN, F., PREDA, M., BORCAN, L.C., PINZARU, I., FLORESCU, S., SISU, E., POENARU, M., Mat. Plast., 55, no. 3, 2018, p. 385.

7. BORCAN, F., SOICA, C.M., LAZUREANU, V., PINZARU, I.A., CHEVERESAN, A., POENARU, M., Mat. Plast., 55, no. 2, 2018, p. 149. 8. BORCAN, L.C., DUDAS, Z., LEN, A., FUZI, J., BORCAN, F., TOMESCU, M.C. Int. J. Nanomed., 13, 2018, p. 7155.

9. ALBULESCU, R.C., BORCAN, F., PAUL, C., VELEA, I., PUIU, M. Int. Curr. Pharm. J., 3, no. 6, 2014, p. 275.

10. BUNGHEZ, F., SOCACIU, C., ZAGREAN, F., POP, R.M., RANGA, F., ROMANCIUC, F. Bull Univ Agricult Sci Vet Med Cluj-Napoca: Food Sci Technol., 70, no. 1, 2013, p. 16.

11. GILL, T.A., LI, J., SAENGER, M., SCOFIELD, S.R. J Appl Microbiol., 121, no. 4, 2016, p. 1103.

12. ALVAREZ ECHAZU, M.I., OLIVETTI, C.E., ANESINI, C., PEREZ, C.J., ALVAREZ, G.S., DESIMONE, M.F. Mater Sci Eng C Mater Biol Appl., 81, 2017, p. 588.

13. ZAMANI, Z., ALIPOUR, D., MOGHIMI, H.R., MORTAZAVI, S.A., SAFFARY, M. Iran J Pharm Res., 14, no. 4, 2015, p. 1031.

15.SALOPEK, B., KRASI, D., FILIPOVI, S., Rudarsko-geoloikonaftnizbornik, 4, 1992, p. 147.

16. CITU, I.M., BORCAN, F., ZAMBORI, C., TITA, B., PAUNESCU, V., ARDELEAN, S., Rev. Chim. (Bucharest), 66, no. 1, 2015, p. 119.

17. GONZALEZ, J., HOU, R.Q., NIDADAVOLU, E.P.S., WILLUMEITROMER, R., FEYERABEND, F. Bioactive Mater., 3, no. 2, 2018, p. 174. 